\title{
Static lung compliance in chronic heart failure: relation with dyspnoea and exercise capacity
}

\author{
S A Evans, L Watson, A J Cowley, I D A Johnston, W J M Kinnear
}

\begin{abstract}
Background - The pathogenesis of dyspnoea in patients with chronic heart failure is poorly understood. Static lung compliance is reduced in chronic heart failure. The relation between static lung compliance and exercise capacity and dyspnoea in chronic heart failure has been investigated.

Methods - Static lung compliance was calculated from expiratory pressure-volume curves in 18 patients with chronic heart failure (three women, mean age 62 years). Catheter mounted pressure transducers were used to measure changes in oesophageal pressure. Changes in lung volume were determined by integrating flow at the mouth, measured by a pneumotachograph. New York Heart Association (NYHA) class for dyspnoea was determined by a single observer. Patients underwent treadmill exercise to symptom limited maximum using staged and fixed rate protocols. Borg ratings for dyspnoea at submaximal exercise were measured.

Results - Static lung compliance, whether expressed as \% total lung capacity (TLC)/ cm $\mathrm{H}_{2} \mathrm{O}$ or \% predicted TLC/cm $\mathrm{H}_{2} \mathrm{O}$, was unrelated to NYHA class. Similarly, there was no relation between static lung compliance and exercise capacity with either protocol or with Borg ratings for dyspnoea at submaximal exercise, with the exception of that measured after 11 minutes of the staged protocol.

Conclusions - Static lung compliance at rest has no relation with treadmill exercise capacity in chronic heart failure, and its relation with measures of dyspnoea is variable. No role for lung elasticity in determining the symptomatology of chronic heart failure was found.

(Thorax 1995;50:245-248)
\end{abstract}

Keywords: chronic heart failure, static lung compliance, dyspnoea, exercise.

University Hospital,

UK

S A Evans

L Watson

A J Cowley

I D A Johnston

W J M Kinnear

Reprint requests to:

Dr S A Evans, Respiratory Unit, Killingbeck Hospital, Leeds LS14 6UQ, UK.

Received 24 February 1994 Returned to authors 29 June 1994

Revised version received 17 October 1994 17 October 1994
Accepted for publication 23 November 1994

The cause of dyspnoea and exercise limitati chronic heart failure is poorly understood, exercise capacity being unrelated to left ventricular function. ${ }^{1-3}$ Several respiratory abnormalities may contribute to dyspnoea and exercise limitation in patients with chronic heart failure including bronchial hyperresponsiveness, ${ }^{4-6}$ respiratory muscle weakness, ${ }^{78}$ hyperventilation secondary to ventilation/perfusion mismatch, ${ }^{9-11}$ stimulation of lung irritant receptors, ${ }^{1213}$ and decreased lung compliance. ${ }^{14-16}$

Pulmonary compliance has previously been shown to be reduced in pulmonary vascular congestion, ${ }^{14-18}$ most of the patients studied having rheumatic mitral valve disease. Data on static lung compliance in patients with heart failure of non-rheumatic origin are lacking. Pulmonary vascular congestion gives a unique pressure-volume curve, with low recoil pressures below functional residual capacity (FRC) and normal maximum transpulmonary pressures at total lung capacity (TLC), in contrast to pulmonary fibrosis. ${ }^{19}$ The relation between reduced lung compliance and increased pulmonary vascular pressures is not known, nor is its role in the origin of dyspnoea and exercise limitation in chronic heart failure. In this study we have sought to examine the relations between static lung compliance and both dyspnoea and exercise performance, with the aim of gaining insight into the role that lung elasticity might play in the dyspnoea experienced by patients with chronic heart failure.

\section{Methods}

The study was approved by the ethical committee of University Hospital, Nottingham, written informed consent being obtained from each patient.

\section{PATIENTS}

Eighteen patients (three women) with chronic heart failure were studied. Their mean age was 62 years (range 48-79) and New York Heart Association class for breathlessness was as follows: class II, $n=7$; class III, $n=10$; class IV, $\mathrm{n}=1$. The aetiology of the chronic heart failure was ischaemic in 12 patients, idiopathic in two, hypertensive in two, and valvular in two. Patients were taking the following medication: frusemide $(n=18)$, angiotensin converting enzyme inhibitors $(n=11)$, long acting nitrates $(n=4)$, digoxin $(n=3)$, calcium channel blockers $(n=2)$. Patients had stable disease with no change in medication during the previous month. All had a cardiothoracic ratio of $>0.5$ on chest radiography and echocardiographic evidence of impaired left ventricular function. Exercise was limited by breathlessness or fatigue in all patients. None were present smokers but 14 were past smokers.
STATIC EXPIRATORY LUNG COMPLIANCE

A catheter mounted pressure transducer (Model CT/S1-2, Gaeltec Ltd, Isle of Skye, UK) was used to measure changes in oesophageal pressure. ${ }^{20}$ The catheter was passed via the nose into the oesophagus and positioned so that the transducer was $10 \mathrm{~cm}$ above the diaphragm. Changes in lung volume were determined by integrating flow at the mouth 
(while wearing a noseclip) which was measured by a pneumotachograph (Fleisch, Switzerland). Static expiratory pressure-volume curves were measured by asking patients to inspire fully and then to expire fully but gently, expiration being interrupted by a balloon intermittently occluding the mouthpiece. Oesophageal pressure and lung volume were recorded during each occlusion. The slope of the pressurevolume curve in the 0.5 litres above FRC was calculated from at least three technically adequate curves. As lung compliance is influenced by lung size ${ }^{19}$ the results were expressed as \% TLC/cm $\mathrm{H}_{2} \mathrm{O}$ and \% predicted TLC/cm $\mathrm{H}_{2} \mathrm{O}$.

\section{CARDIAC OUTPUT}

Resting cardiac output was measured by an indirect Fick principle with carbon dioxide as the indicator. This technique has good agreement when compared with thermodilution. ${ }^{21}$

\section{PULMONARY ARTERY PRESSURE}

Resting pulmonary artery pressure was calculated from measuring the jet of tricuspid regurgitation using pulsed Doppler techniques with two dimensional echocardiography. ${ }^{22}$ Adequate signals were obtained in 15 of the 18 subjects.

\section{EXERCISE PROTOCOLS}

Patients were exercised to symptom limited maximum using two different treadmill protocols: an incremental exercise test (modified Bruce protocol) and a fixed protocol. During the incremental protocol the speed and slope of the treadmill were increased as shown in the table. During the fixed protocol the speed $(\mathrm{km} /$ hour) and the slope $\left(4.3^{\circ}\right)$ were constant at the equivalent of stage 4 of the incremental protocol.

\section{MEASURES OF DYSPNOEA}

NYHA class for dyspnoea was determined by a single observer (SAE). Borg ratings for dyspnoea ${ }^{23}$ at submaximal exercise were obtained by holding a card in front of the patient while undertaking treadmill exercise and asking which number best described how their breathing felt. This was repeated after each minute of both protocols.

\section{LUNG VOLUMES}

Total lung capacity was measured by the helium dilution method (PK Morgan, Kent, UK). Predicted values were taken from Cotes. ${ }^{24}$

\section{CARDIAC VOLUME}

Cardiac volume was estimated from chest radiographs as previously described. ${ }^{25}$

Exercise protocol

\begin{tabular}{lllllll}
\hline & \multicolumn{6}{l}{ Stage } \\
\cline { 2 - 6 } & 1 & 2 & 3 & 4 & 5 & 6 \\
\hline Speed $(\mathrm{km} / \mathrm{h})$ & $2 \cdot 7$ & $2 \cdot 7$ & $2 \cdot 7$ & $2 \cdot 7$ & $4 \cdot 0$ & $5 \cdot 5$ \\
Slope $\left({ }^{\circ}\right)$ & 0 & $1 \cdot 3$ & $2 \cdot 6$ & $4 \cdot 3$ & $5 \cdot 4$ & $6 \cdot 3$ \\
\hline
\end{tabular}

\section{DATA ANALYSIS}

The relation between static lung compliance and treadmill exercise time, Borg ratings for dyspnoea, cardiac index, cardiac volume, and estimated pulmonary artery pressure were evaluated using the Spearman rank correlation coefficient. The relation between static lung compliance and NYHA class II and III was investigated using an unpaired Student's $t$ test. The level of statistical significance was taken as $0 \cdot 05$.

\section{Results}

Mean (SD) static lung compliance was 188 (78) $\mathrm{ml} / \mathrm{cm} \mathrm{H}_{2} \mathrm{O}$, being alternatively expressed as $3.6(0.8) \% \mathrm{TLC} / \mathrm{cm} \mathrm{H}_{2} \mathrm{O}$ or $3.07(1.03) \%$ predicted $\mathrm{TLC} / \mathrm{cm} \mathrm{H}_{2} \mathrm{O}$. As expected, absolute static lung compliance correlated with TLC $(r=0.8, \mathrm{p}<0.001$, fig 1$)$ and $\%$ predicted TLC $(r=0.74, \mathrm{p}<0.001)$.

Mean symptom limited exercise times for the incremental and fixed protocols were 523 (268) seconds and 389 (279) seconds, respectively. There was no significant relation between static lung compliance and exercise time with either protocol (fig 2). Static lung compliance remained unrelated to Borg ratings for dyspnoea at each successive minute during both exercise protocols, with the exception of that measured after 11 minutes of the incremental protocol $(r=0 \cdot 8, \mathrm{p}<0 \cdot 05)$. Static lung compliance was also unrelated to the rate of increase in Borg score during exercise.

Whilst mean staticlung compliance expressed as $\mathrm{ml} / \mathrm{cm} \mathrm{H}_{2} \mathrm{O}$ was significantly related to NYHA class (class II 232 (91) $\mathrm{ml} / \mathrm{cm} \mathrm{H}_{2} \mathrm{O}$ versus class III 159 (53) $\mathrm{ml} / \mathrm{cm} \mathrm{H}_{2} \mathrm{O}, \mathrm{p}<0.05$, fig $3 \mathrm{~A})$, this was not the case if static lung compliance was expressed as $\% \mathrm{TLC} / \mathrm{cm} \mathrm{H}_{2} \mathrm{O}$ (class II $3 \cdot 8(1 \cdot 2)$ versus class III $3.5(0.6), \mathrm{p}=\mathrm{NS}$, fig $3 \mathrm{~B}$ ) or as $\%$ predicted $\mathrm{TLC} / \mathrm{cm} \mathrm{H}_{2} \mathrm{O}$ (class II $3 \cdot 6(1 \cdot 3)$ versus class III $2 \cdot 7(0 \cdot 7), \mathrm{p}=\mathrm{NS})$.

Mean pulmonary artery pressure at rest was $37 \cdot 7(17 \cdot 7) \mathrm{mm} \mathrm{Hg}$ and was not significantly related to any expression of static lung compliance. Mean cardiac index was $2 \cdot 26(0 \cdot 48)$ $1 / \mathrm{min} / \mathrm{m}^{2}$ and, though related to static lung compliance expressed as \% TLC/cm $\mathrm{H}_{2} \mathrm{O}(r=$ $-0.48, \mathrm{p}<0.05)$, was not related to absolute static lung compliance or to static lung compliance expressed as \% predicted TLC/cm $\mathrm{H}_{2} \mathrm{O}$. Mean cardiac volume was 1446 (419) $\mathrm{ml}$ but no relation with any expression of static lung compliance was observed.

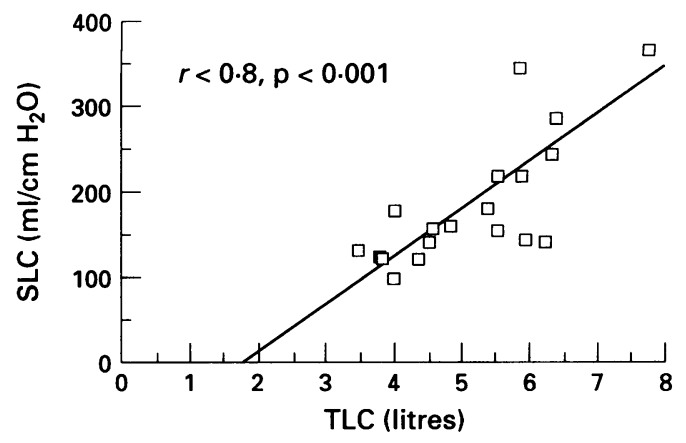

Figure 1 Relation between static lung compliance (SLC) and total lung capacity (TLC). 


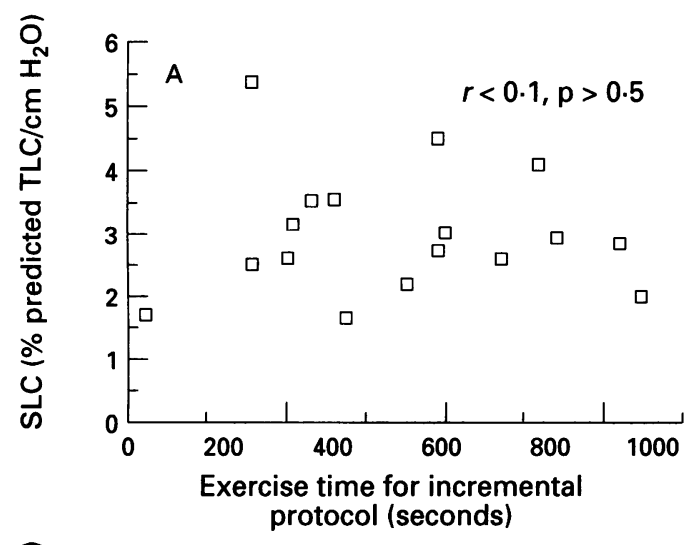

such as NYHA class or Borg ratings in chronic heart failure. We have also shown that static lung compliance is not related to resting pulmonary artery pressure or cardiac index in this condition. Lung elasticity at rest would therefore seem not to be a major determinant of the dyspnoea and reduced exercise capacity experienced in chronic heart failure.

Previous studies have shown a reduction in static lung compliance in patients with rheumatic heart disease compared with normal subjects. ${ }^{1516} 18$ Most patients in the present study had non-valvular heart disease and static lung compliance in this population was found

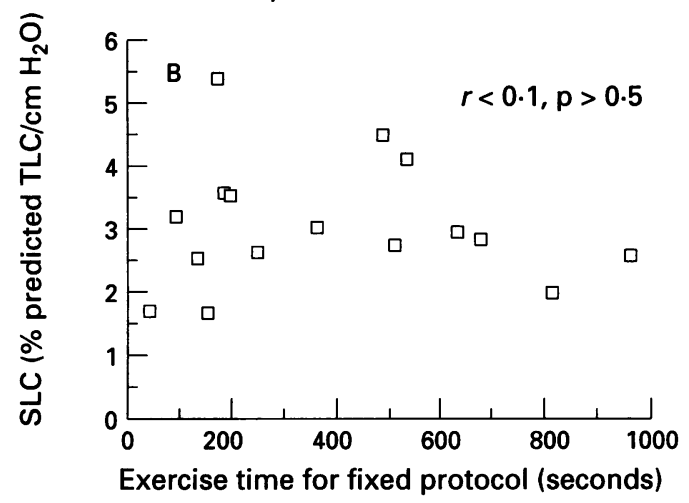

Figure 2 Relation between static lung compliance (SLC) and treadmill exercise time on $(A)$ incremental protocol and (B) fixed protocol.
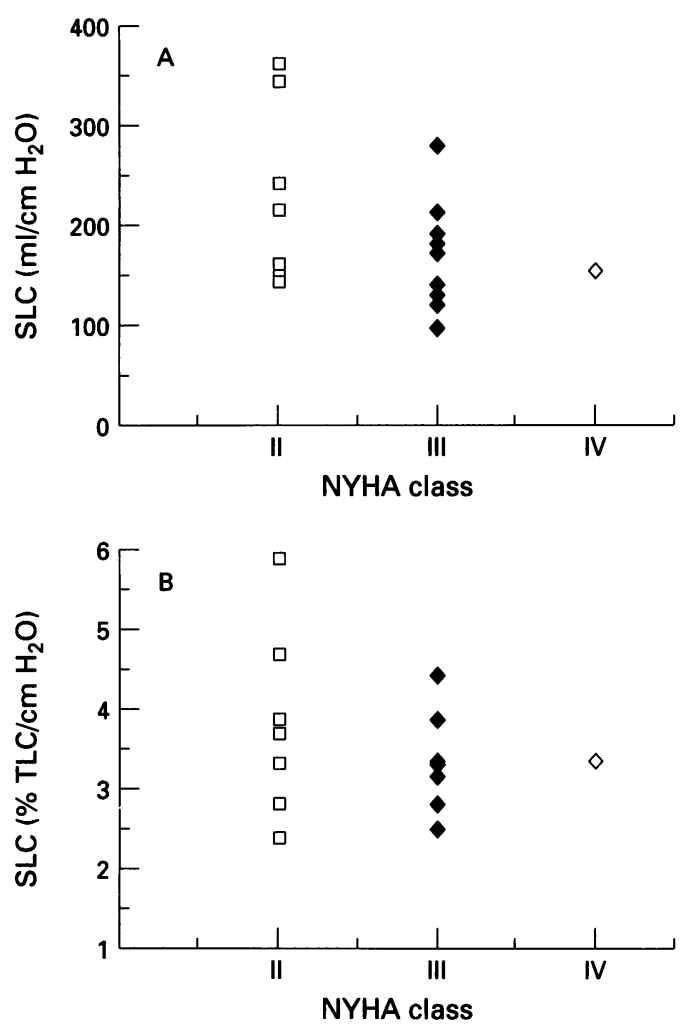

Figure 3 Relation between absolute static lung compliance (SLC) and New York Heart Association (NYHA) class (NYHA II v III, $p<0.05$ ) and (B) relation between static lung compliance expressed as \% relation between static lung compliance expressed as $\%$ (NYHA II $v$ III, $p=N S)$.

\section{Discussion}

This study has shown that static lung compliance at rest is not related to treadmill exercise capacity or, in general, to measures of dyspnoea to be similar to that in patients with mitral stenosis. ${ }^{16}$ Dynamic lung compliance has also been shown to be reduced in rheumatic heart disease $^{1416}$ but this measurement reflects not only lung elasticity but also airway resistance. ${ }^{19}$ Dynamic lung compliance was not measured in the present study as we specifically wished to investigate the role of lung elasticity, having previously shown that exercise capacity and dyspnoea in chronic heart failure are not related to the degree of airways obstruction present. ${ }^{26}$

Why is static lung compliance reduced in chronic heart failure? Absolute static lung compliance $\left(\mathrm{ml} / \mathrm{cm} \mathrm{H}_{2} \mathrm{O}\right)$ in normal individuals correlates well with lung volumes and probably reflects the greater number of alveoli in the lungs of tall people. ${ }^{1927}$ It is thought that the reduction in static lung compliance seen in fibrosing alveolitis is a result of a reduction in functioning alveoli ${ }^{1928}$ and this may also be the case in chronic heart failure. The close relation between absolute static lung compliance and TLC demonstrated in the present study, and reduced regional ventilation in chronic heart failure, ${ }^{2930}$ are both consistent with this hypothesis. The shape of the pressure-volume curve in chronic heart failure is different from that seen in fibrosing alveolitis, however, with the flattening of the curve being partly due to abnormally low transpulmonary pressures at low lung volumes (whereas in fibrosing alveolitis transpulmonary pressure is high at all lung volumes). ${ }^{1619}$ This characteristic might be due to an engorged pulmonary bed keeping the lung expanded at low lung volumes ${ }^{1719}$ as a result of raised pulmonary capillary pressures. If this was the case one might expect to see a relation between pulmonary artery pressure and static lung compliance, but this was not observed in the present study. Another possible cause of decreased static lung compliance in chronic heart failure is a decrease in the space in which the lungs may expand within the thoracic cage as a result of cardiomegaly or pleural effusions, ${ }^{19}$ but we found no relation between cardiac volume and static lung compliance in this study. The relation between static lung compliance and TLC is consistent with this hypothesis, however.

There are several possible reasons why no relation was found between static lung compliance and measures of dyspnoea in chronic heart failure. Firstly, the repeatability of static lung compliance is relatively poor. In our laboratory static lung compliance has a coefficient of repeatability ${ }^{31}$ of $50-80 \mathrm{ml} / \mathrm{cm} \mathrm{H}_{2} \mathrm{O}$ - that is, 
$23-37 \% .^{32}$ The demonstration of the expected relation between TLC and static lung compliance in the present study, however, suggests that the reproducibility of static lung compliance is adequate to assess relations with other factors. Secondly, the use of continuous scale measurements of dyspnoea such as Borg scores for comparison between patients is subject to great variation. ${ }^{33}$ Thirdly, the study included patients who were past smokers and may therefore have undetected emphysema. This could result in unexpectedly high static lung compliance values and thus obscure any relation sought. The most likely explanation, however, is that static lung compliance is indeed not an important determinant of dyspnoea in chronic heart failure. It remains possible that static lung compliance may be a factor at the extremes of exercise given our finding of a relation between static lung compliance and dyspnoea after 11 minutes of the incremental protocol, but this must be interpreted with caution since data were available for only seven patients. Further study of whether changes in static lung compliance reflect changes in dyspnoea might provide useful additional information. Thus, while we have found no convincing relation between static lung compliance at rest and dyspnoea in chronic heart failure, we did not study the changes that occur on exercise. Static lung compliance may change during exercise in chronic heart failure and this could potentially give rise to dyspnoea. Measuring lung elasticity during exercise is likely to be difficult, however. It is doubtful if breathless patients could tolerate interrupted expiratory manoeuvres during exercise and reproducibility would probably be poorer. Given the impracticality of measuring static lung compliance during exercise we used resting values. Many investigators have studied the relationship between exercise capacity and resting values for central and peripheral cardiovascular variables known to change during exercise and some significant relations have been found. ${ }^{3435}$ It therefore seemed reasonable to examine the relation between exercise capacity and a resting respiratory variable.

We conclude that static lung compliance measured at rest is unrelated to dyspnoea or exercise capacity in patients with chronic heart failure. We have been unable to show a role for lung elasticity in determining the symptomatology of chronic heart failure, but without examining changes in static lung compliance during exercise its relevance remains uncertain.

1 Szlachlic J, Massie BM, Kramer BL, Topic N, Tubau J Correlates and prognostic implication of exercise capacity in chronic congestive heart failure. Am $\mathcal{f}$ Cardiol 1985;55 1037-42.

2 Franciosa JA, Baker JB, Seth L. Pulmonary versus systemic haemodynamics in determining exercise capacity of patients with chronic left ventricular failure. Am Heart $\mathfrak{f}^{\prime}$ 1985;110:807-13.

3 Meiler SE, Ashton JJ, Moeschberger ML, Unverferth DV, Leier CV. An analysis of the determinants of exercise performance in congestive heart failure. Am Heart $\mathcal{F} 1987$; performance

4 Cabanes LR, Weber SN, Matran R, Regnard J, Richard MO, Degeorges ME, et al. Bronchial hyperresponsiveness to methacholine in patients with impaired left ventricular function. N Engl F Med 1989;320:1317-22.

5 Pison C, Malo J, Rouleau J, Chalaoui J, Ghezzo H, Malo J. Bronchial hyperresponsiveness to inhaled methacholine in subjects with chronic left heart failure at a time of in subjects with chronic left heart failure at a time of 1989;96:230-5.

6 Sasaki F, Ishizaki T, Mifune J, Fujimura M, Nishioka, Miyabo S. Bronchial hyperresponsiveness in patients with chronic congestive heart failure. Chest 1990;97:534-8.

7 Hammond MD, Bauer KA, Sharp JT, Rocha RD. Respiratory muscle strength in congestive heart failure. Chest 1990;98:1091-4.

8 McParland C, Krishnan B, Wang Y, Gallagher CG. Inspiratory muscle weakness and dyspnea in chronic heart spiratory muscle weakness and dyspnea in chro

9 Sullivan MJ, Higginbotham MB, Cobb FR. Increased exercise ventilation in patients with chronic heart failure: intact ventilatory control despite haemodynamic and pulmonary abnormalities. Circulation 1988;77:662-9.

10 Davies SW, Emery TM, Watling MIL, Wanamethee G, Lipkin DP. A critical threshold of exercise capacity in the ventilatory response to exercise in heart failure. Br Hear f 1991;65:179-83.

11 Buller NP, Poole-Wilson PA. Mechanism of the increased ventilatory response to exercise in patients with chronic ventilatory response to exercise in patie
heart failure. Br Heart $\mathcal{f} 1990 ; 63: 281-3$.

12 Sellick H, Widdicombe JG. The activity of lung irritant receptors during pneumothorax, hyperpnoea and pulmonary vascular congestion. F Physiol 1969;203:359-81.

13 Paintal AS. Mechanism of stimulation of type J pulmonary receptors. F Physiol 1969;203:511-32.

14 Christie RV, Meakins JC. The intrapleural pressure in congestive heart failure and its clinical significance. 7 Clin Invest 1934;13:323-45.

15 Frank NR, Lyons HA, Siebens AA, Nealon TF. Pulmonary compliance in patients with cardiac disease. $A m \mathcal{F} M e d$ compliance in patie

16 Wood TE, McLeod P, Anthonisen NR, Macklem PT. Mechanics of breathing in mitral stenosis. Am Rev Respir Dis 1971;104:52.

17 von Basch S. Uber eine function des capillardruckes in den lungenalveolen. Wien $\mathrm{Med} \mathrm{Bl}$ 1887;10:446.

18 Brown CC, Fry DL, Ebert RV. The mechanics of pulmonary ventilation in patients with heart disease. $A m \mathcal{F} M e d 1954$; 17:438-46.

19 Gibson GJ, Pride NB. Lung distensibility: the static pressure-volume curve of the lungs and its use in clinical assessment. Br $\mathcal{F}$ Dis Chest 1976;70:143-84

20 Evans SA, Watson L, Cowley AJ, Johnston IDA, Kinnear WJM. Normal range for transdiaphragmatic pressures during sniffs using catheter mounted transducers. Thorax 1993;48:750-3.

21 Cowley AJ, Stainer K, Murphy DT, Murphy J, Hampton JR. A non-invasive method of measuring cardiac output: the effect of Christmas lunch. Lancet 1986;ii:1422-3.

22 Marchandise B, De Bruyne B, Delaunois L, Kremer R. Noninvasive prediction of pulmonary hypertension in chronic obstructive pulmonary disease by Doppler echochronic obstructive pulmonary disease
cardiography. Chest 1987;91:361-5.

23 Borg G. Psychophysical bases of perceived exertion. Med Sci Sports Exerc 1982;14:377-81.

24 Cotes JE. Lung function, assessment and application in medicine 4th edn. Oxford: Blackwell Scientific, 1979:365-87.

25 Evans DW, Carpenter PB. Errors involved in radiological heart volume determination of the ellipsoid approximation techniques. Br Heart f 1965;27:429-39.

26 Evans SA, Kinnear WJ, Cowley AJ, Johnston IDA. Does airway obstruction and bronchial hyperresponsiveness airway obstruction and bronchial hyperresponsiveness Rev Respir Dis 1993;147:A171.

27 Angus GE, Thurlbeck WM. Number of alveoli in the human lung. F Appl Physiol 1972;32:483-5.

28 Gibson GJ, Pride NB. A reappraisal of lung mechanics in fibrosing alveolitis. Chest 1976;69(Suppl):256

29 Mohensifar Z, Amin DK, Shah PK. Regional distribution of lung perfusion and ventilation in patients with chronic congestive heart failure and its relation to cardiopulmonary haemodynamics. Am Heart $₹$ 1989;117:887-91.

30 Dawson A, Rocamora JM, Morgan JR. Regional lung function in chronic pulmonary congestion with and without mitral stenosis. Am Rev Respir Dis 1976;113:51-9.

31 Bland JM, Altman DG. Statistical methods for assessing agreement between two methods of clinical measurement. Lancet 1986;i:307-10.

32 Evans SA, Kinnear WJM, Watson L, Cowley AJ, Johnston IDA. Computerised system for measuring static lung compliance: is ECG synchronisation necessary? Eur Respir $\mathscr{f}$ 1993;6(suppl 7):458s.

33 Adams L, Chronos N, Lane R, Guz A. The measuremen of breathlessness induced in normal subjects: individua differences. Clin Sci 1986;70:131-40.

34 Baker JB, Wilen MM, Boyd CM, Dihn H, Franciosa JA Relation of right ventricular ejection fraction to exercise capacity in left ventricular failure. Am 7 Cardiol 1984;54. 596-9.

35 Cowley AJ, Stainer K, Rowley JM, Hampton JR. Abnormalities of the peripheral circulation and respiratory
function in patients with severe heart failure. $\mathrm{Br}$ Heart $\mathcal{f}$ 1986;55:75-80. 